\title{
Innovative education networking aimed at multimedia tools for geometrical optics learning
}

P. García-Martínez, C. Zapata-Rodríguez, C. Ferreira, I. Fernández, D. Pastor, et al.

P. García-Martínez, C. J. Zapata-Rodríguez, C. Ferreira, I. Fernández, D. Pastor, M. Nasenpour, I. Moreno, M. M. Sánchez-López, J. Espinosa, D. Mas, J. J. Miret, "Innovative education networking aimed at multimedia tools for geometrical optics learning," Proc. SPIE 9793, Education and Training in Optics and Photonics: ETOP 2015, 97930L (8 October 2015); doi:

10.1117/12.2223077

Event: Education and Training in Optics and Photonics: ETOP 2015, 2015, Bordeaux, France 


\title{
Innovative Education Networking Aimed at Multimedia Tools for Geometrical Optics Learning
}

\author{
P. García-Martínez ${ }^{1}$, C. J. Zapata-Rodríguez ${ }^{1}$, C. Ferreira ${ }^{1}$, I. Fernández ${ }^{1}$, D. Pastor ${ }^{1}$, M. Nasenpour ${ }^{1}$, I. Moreno ${ }^{2}$, \\ M. M. Sánchez-López ${ }^{3}$, J. Espinosa ${ }^{4}$, D. Mas ${ }^{4}$ and J. J. Miret ${ }^{4}$ \\ ${ }^{1}$ Department of Optics, Universitat de València, 46100 Burjassot, Spain \\ ${ }^{2}$ Departamento de Ciencia de Materiales, Óptica y Tecnología Electrónica, Universidad Miguel Hernández, 03202 \\ Elche, Spain \\ ${ }^{3}$ Instituto de Bioingeniería, Universidad Miguel Hernández, 03202 Elche, Spain. \\ ${ }^{4}$ Departament d'Òptica, Farmacologia i Anatomia. Universitat d'Alacant. 03690 Alicante, Spain.
}

\begin{abstract}
We present a purposeful initiative to open new grounds for teaching Geometrical Optics. It is based on the creation of an innovative education networking involving academic staff from three Spanish universities linked together around Optics. Nowadays, students demand online resources such as innovative multimedia tools for complementing the understanding of their studies. Geometrical Optics relies on basics of light phenomena like reflection and refraction and the use of simple optical elements such as mirrors, prisms, lenses, and fibers. The mathematical treatment is simple and the equations are not too complicated. But from our long time experience in teaching to undergraduate students, we realize that important concepts are missed by these students because they do not work ray tracing as they should do. Moreover, Geometrical Optics laboratory is crucial by providing many short Optics experiments and thus stimulating students interest in the study of such a topic. Multimedia applications help teachers to cover those student demands. In that sense, our educational networking shares and develops online materials based on 1) video-tutorials of laboratory experiences and of ray tracing exercises, 2) different online platforms for student self-examinations and 3) computer assisted geometrical optics exercises. That will result in interesting educational synergies and promote student autonomy for learning Optics.
\end{abstract}

\section{INTRODUCTION}

Spanish Higher Education has transformed teaching methods and structures by Bologna process ${ }^{1}$ in the last six years. The academic methodology focused now on the student's autonomous learning rather than in the role of mere information receptor. In that sense, students need many new tools and teaching material to accomplish such autonomous learning process, because there is some evidences that traditional approaches are ineffective in teaching physics concepts, including light and optics concepts ${ }^{2}$. Digital technologies resources provides researchers in general and teachers in particular interesting tools that can be used to improve both the flux and exchange of information and also the teaching-learning process ${ }^{3}$. Electronic Learning or e-learning is a type of technology-supported education learning using computer technology such as online classrooms, however one of the main drawbacks is the lack of social interaction. In that sense, blended learning (b-learning) ${ }^{4}$ combines both technology and regular teaching methods (face to face lessons, lab sessions, guidance and coaching).

Networking is done at many levels, in many fields. A "network" according to the meaning here is a web of interconnected people sharing an interest in the success of a particular enterprise. Photonics educators can benefit from being better connected to each other, not just to information. In that sense, the department of Policy Training and Educational Quality of the University of Valencia, in Spain, has bet on innovative education networking. The requirements to apply for that kind of innovative project is to be minimum ten teachers and three universities from Spanish territory. The aim of our network is to develop b-learning tools for Geometrical Optics and the network is composed by University of Alicante, the University of Miguel Hernández in Elche and the University of Valencia. The academic networking staff is expert in Optics teaching and more specifically in Geometrical Optics.

Education and Training in Optics and Photonics: ETOP 2015, edited by Eric Cormier, Laurent Sarger Proc. of SPIE Vol. 9793, 97930L · C 2015 SPIE, IEEE, OSA, ICO · doi: 10.1117/12.2223077 
Geometrical optics help to understand the basics of light reflection and refraction and the use of simple optical elements such as mirrors, prisms, lenses, and fibers. In fact Geometrical Optics has the strange ability to be a quite simple topic, due to the easy mathematical treatment, but on the other side, it results in a difficult and complex understandable subject for students. In fact, physics students some times are more comfortable studying complex Quantum Mechanics equations that understanding the virtual imaging of thin lenses. We think that what is really missing is that Geometrical Optics needs to be seen and drawn. A simple ray tracing explain in an easy way any optical system. Students have to be familiar to ray tracing techniques and also to touch prism, lenses, mirrors, etc. in the laboratory to learn Geometrical Optics properly. Emerging computer technologies and new understanding of student learning difficulties can help us make geometrical optics programs more engaging and effective. As famous quote by Confucius says, "I hear and forget, I see and remember, I do and I understand", so this is. Our network has developed a series of educational multimedia tools for learning Geometrical Optics. Such tools are based on interactive learning multimedia exercises to improve the ray tracing practice ${ }^{5}$, video-tutorials for both laboratory activities and for ray tracing and also online examination tests. In Figure 1 we show our home web page where all those learning tools are linked together.

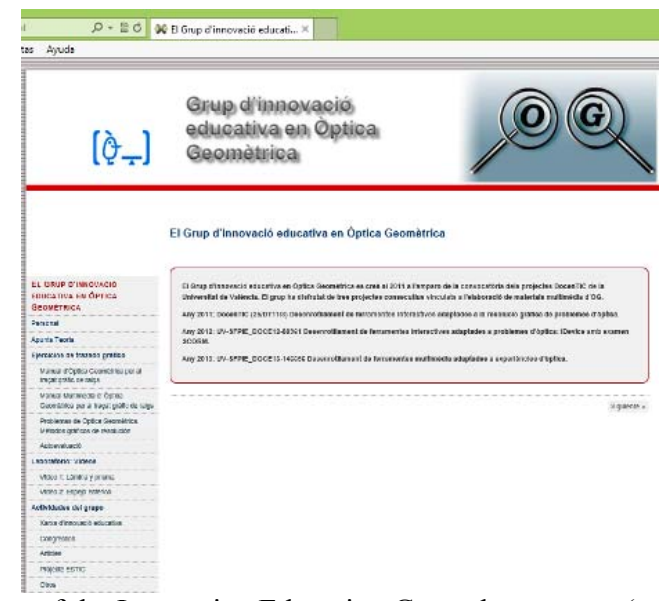

Figure 1: Snapshot of the Innovative Education Group home page (www.uv.es/ioptica)

The manuscript is organized as follows: in Section 2 we explain our interactive learning multimedia exercises. Videotutorials and online examination tests are in Section 3 and 4, respectively. Conclusion are depicted in Section 5.

\section{INTERACTIVE LEARNING MULTIMEDIA EXERCISES}

The multimedia educational material that has been developed has the following characteristics:

1. The student is offered a set of 24 exercises solved using only graphical tools for optical ray tracing. The approach of each exercise is based on a multiple-answer operative scheme, which can only be answered correctly after the graphic resolution of the problem (see Fig. 2).

2. Prior to the approach of every problem, a brief theoretical introduction is advanced, which contextualizes such problem.



Figure 2: Snapshot from webpage of problem 14 posed by imaging through a thin lens doublet 
3. Multiple viewports have been incorporated to show the exercise approach and the progressive resolution of the given problem.

4. The graphic resolution of the problem can be performed after printing the corresponding diagram (see Fig. 3). This simple action is activated by a button that has been inserted for such purpose. Also we can print it using the Print button on the toolbar, or the Print option in the File menu.

5. It allows for easy inclusion in multimedia environments of diverse nature such as Virtual Classroom, personal or corporate websites, as embodied nowadays.

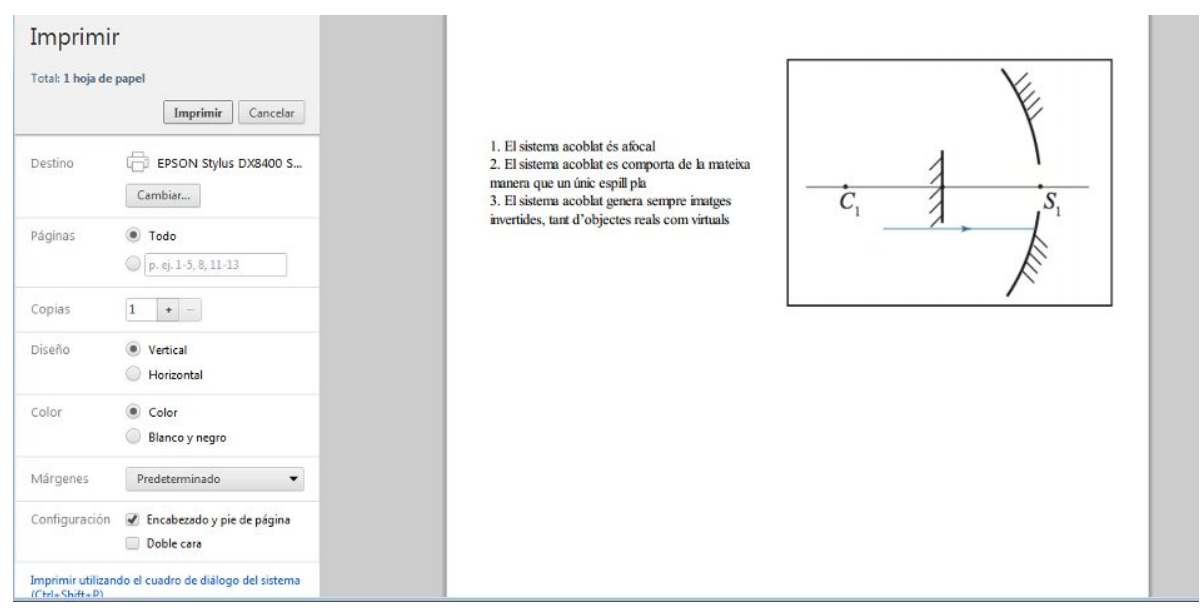

Figure 3: Image where the activated Print option is observed

The interactive tool that we developed has the additional objective of impact very directly on non-attendance and independent study of a student. For this reason, this tool is mainly based on problem solving specifically designed for self-study. The material incorporates the necessary elements that allow students to know the degree of success in solving the proposed problems.

It should be noted that this teaching material that we have done also supports synchronous tools for conducting tutorials and virtual classrooms as Elluminate, which are proposed actions for the immediate future. Finally, these teaching contents have been deposited in Roderic (Repositori d'Objectes Digitals per a l'Ensenyament la Recerca i la Cultura) which is the institutional repository of University of Valencia and free access to the entire university community (http://roderic.uv.es/handle/10550/24448).

We have also carried out a quality survey of the results obtained by interacting with students enrolled in the current academic year 2012-2013 within the module "Physics II. Geometrical Optics," in Optics and Optometry Basic Degree, which have already used such interactive learning material. The intent of this action was to check that the adaptation of the contents of the manual ${ }^{6,7}$ within our multimedia platform creates a friendlier environment, which primarily aims to alleviate the difficulty in understanding Geometrical Optics problems when only using books text. This process has been developed by custom interviews to some of these students and evaluation of a quality survey responded for all students. The result of the survey evaluation has prompted us to interesting conclusions. These include that all the material to be disclosed, including website and pdf, etc, must be used wholly or partly in contact sessions. We have found that if teachers do not use this material in class but simply announce its existence, the students will use either little or none of it. Another interesting point is that the students prefer educational platforms based on teaching material including explanatory videos. And finally, for $92 \%$ of students, these materials are considered necessary for the study of the Optics subject. This assessment of the obtained results allow us to correct errors that may have been committed and improve specific aspects of the developed educational material.

\section{VIDEO-TUTORIALS FOR SELF-ASSESSMENT}

The video format is familiar to students, contains a wealth of spatial and temporal data, and provides a bridge between direct observations and abstract representations of physical phenomena ${ }^{8}$. Video-tutorials enhance and speed up the 
learning process due to the visually easy followed procedures step by step. In fact, we started to work on video-tutorials due to the insistent student demands. They claim that before going to the laboratory it will be worthy to visualize materials, procedure and a summary of the laboratory exercise by video-tutorials. In that sense, they would take profit and understand the subject properly having this visual information in advance. In fact, in 2012 we conducted a survey to 70 students asking which of the following teaching materials: pdf files, interactive multimedia resources and videotutorials, the most demanded was video-tutorials.

We have recorded two kinds of video-tutorials for Geometrical Optics learning, one for laboratory exercises and the other for ray tracing optical systems.

\subsection{Video-tutorials for Geometrical Optics Laboratory}

Our experience in teaching Geometrical Optics for many academic courses reveals that taking laboratory experiences related to the image formation through optical systems is fundamental to understand the subject properly. Solving the problems in the laboratory should help you explain many of student daily experiences with images with the concept of light rays that travel from sources or illuminated objects in straight lines. We have prepared two video-tutorials for prism and plane parallel glass tracing and also for concave spherical mirror imaging.

Regarding the study of refraction in a prism and a plane parallel glass, we simulate light rays using pins nailed in a cork plate. After observing the ray displacement and measuring some refraction angles we calculate the index of refraction of the glass (see Fig. 4).
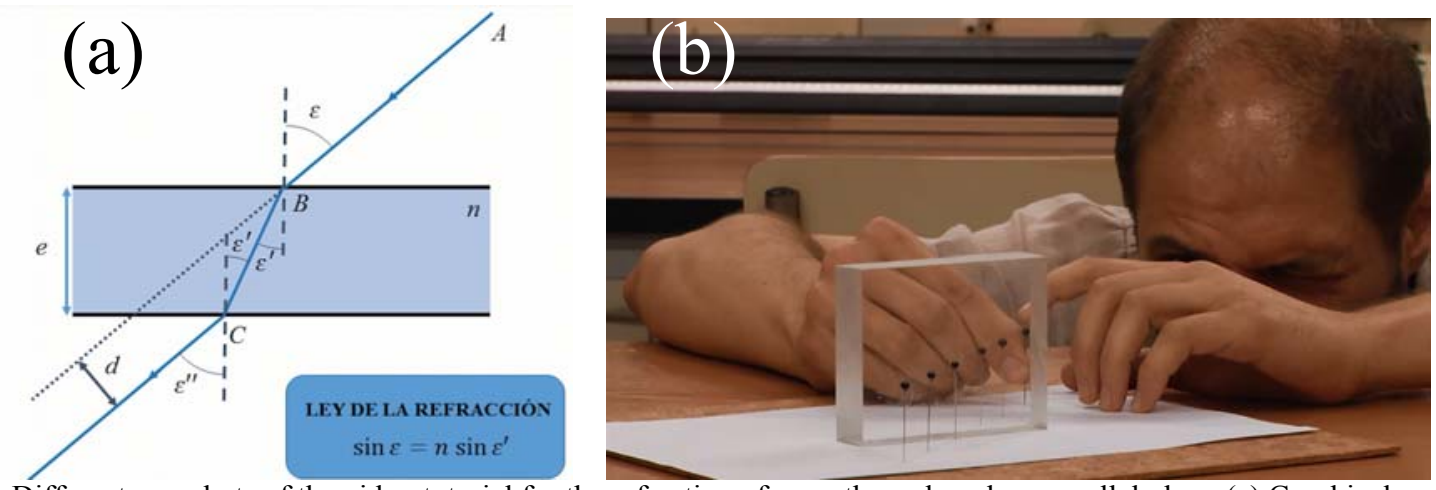

Figure 4: Different snapshots of the video-tutorial for the refraction of a ray through a plane parallel glass. (a) Graphical ray tracing

(b) Experiment

We also calculate the refraction index of a prism by measuring the deviation of an incident light beam emerging though a prism (see Fig. 5).

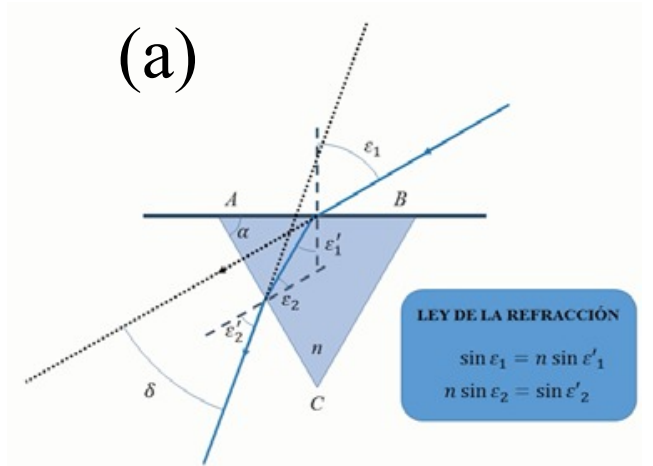

Figure 5: Different snapshots of the video-tutorial for the refraction of the light though a prism. Experiment

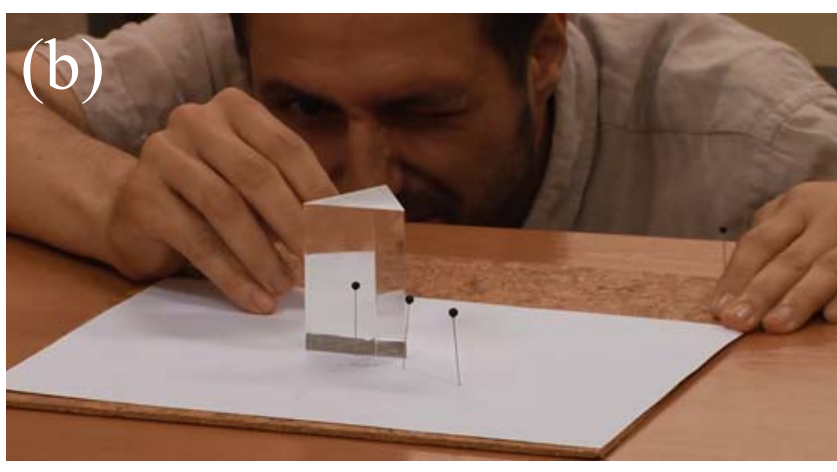

(a) Graphical ray tracing (b) 
Imaging formation by spherical concave mirror is another interesting experiment of our optics laboratory. Here students observe real imaging and measure their positions in order to calculate the focal distance of the mirror (see Fig. 6).



a)


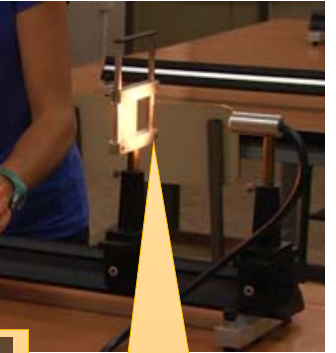

OBJECT

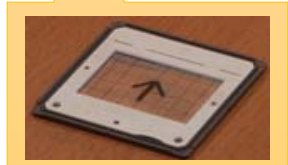

Figure 6: Different snapshots of the video-tutorial for the image formation of a spherical mirror. (a) Graphical ray trace (b) Experiment

Both videos have a duration of ten minutes aproximately. At the beginning of the video-tutorial we review the theory and we clarify the objective of the practice. Then, we show the different optical components that are needed and we implement the experiment putting spetial attention in recording the relevant parts of the experiment.

\subsection{Video-tutorials for Graphical Ray Tracing (ESTIC Program)}

Using our interactive manual ${ }^{6,7}$, a group of 8 students enrolled in the module "Physics II. Geometric Optics" during the 2011-2012 academic year, has found that the use of short videos would create an alternative and very attractive environment for understanding the resolution of exercises in the interactive manual. ESTIC program aims to promote, recognize and accredit the work done by groups of students of the University of Valencia who incorporate their processes of learning information and communication technologies and cooperative and/or collaborative methodologies. Within the ESTIC (www.uv.es/udie/estic.htm) Univeristy of Valencia program, that group of our students has carried out a proposal that involves the development of a series of videos leading to the resolution of some issues included in manual ${ }^{6,7}$ and interactive tool that we have detailed in previous sections. So far there have been incorporated a total of 7 videos. However, there is great interest in continuing to include new videos that complete the existing supply.

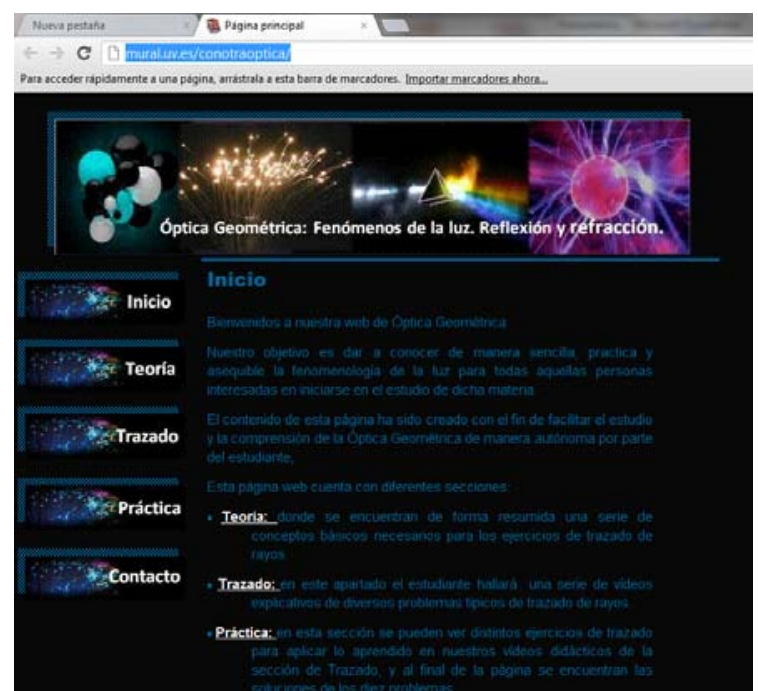

Figura 7: Homepage of ESTIC project developed by students of GO in partnership with our project (http://mural.uv.es/conotraoptica) 
This work is complemented by the construction of a customized web page (see Fig. 7) on which to upload these videos (mural.uv.es/conotraoptica). These multimedia teaching materials has been added to our own interactive web platform.

\section{EXAMINATION ONLINE TEST}

Other aim of this network is to assess the degree of assimilation by students of the basic concepts of Geometrical Optics so colleagues from the University of Alicante that are participants in our educational network have created online test with Hot Potatoes. This program has the advantage of being able to easily add images, formulas and even animations that versatility that can address the variety of concepts involved in the subjects. It is intended to implement this tool at the end of each unit providing the student a guidance note of their basic knowledge and thus helping them discover their weaknesses or deficiencies.

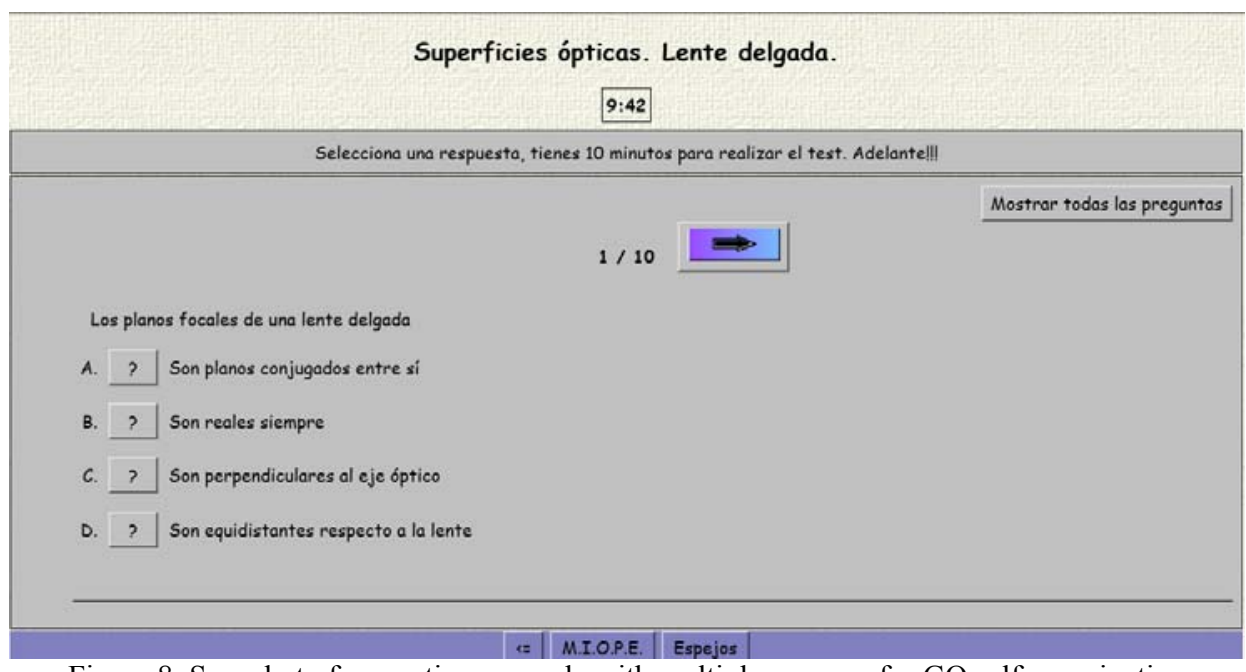

Figura 8: Snapshot of a question example with multiple answers for GO self-examination

Students may answer in a 10 minutes test, ten questions about different aspects that have been explained in each unit. After the test, the grade obtained is displayed in the web page.

\section{CONCLUSIONS}

The department of Policy Training and Educational Quality of the University of Valencia has created an innovative education networking involving academic staff from three Spanish universities linked together around Optics. Nowadays, students demand online resources such as innovative multimedia tools for complementing the understanding of their studies. We have tried to merge the teaching experience in Geometrical Optics of some teachers from different Spanish Universities to develop learning tools in order to improve the autonomous work of students. We have shown in this contribution an interactive multimedia platform for graphical ray tracing, video-tutorials based on laboratory practices and also different online self-examination tests.

\section{ACKNOWLEDGEMENTS}

This work was supported by the Vicerectorat de Polítiques de Formació i Qualitat Educativa de la Universitat de València (Project UV-SFPIE_DOCE14-222505). We gratefully acknowledge the tecnincal assistance in audiovisual editing and web programming of Mrs. Verónica Pardo Sánchez from Centre de Formació i Qualitat "Manuel Sánchez Guarner". We also thank the collaboration of former undergraduate students Mr. Diego Montagud Martínez and Ms. Celeste Briceño López, from ESTIC Program. 


\section{REFERENCES}

1. "The Bologna Process-Towards the European Higher Education Area", European Commission, http://ec.europa.eu/education/policy/higher-education/bologna-process_en.htm (June 2015).

2. David R. Sokoloff, Ronald K. Thornton and Priscilla W. Laws, "Real Time Physics: Active Learning Labs

Transforming the Introductory Laboratory", Eur. J. of Phys 28 S83-S94 (2007).

3. T. Martin-Blas "E-learning platforms in Physics Education", Chapter in Technology, Education and Development INTECH Open Access Publisher (2009).

4. A. Heinze and C. Procter, "Refection on the use of Blended Learning" Proceedings of the second Education in Changing Environment conference ISBN: 0902896806, Manchester, UK, $13^{\text {th }}-14^{\text {th }}$ September 2004, Published by the University of Salford Manchester.

5. C. J. Zapata-Rodríguez, P. García-Martínez, C. Ferreira, I. Fernández and J. J. Miret, "Interactive resources for efficient tutoring and e-learning in Optics based on solving problems with graphics," Opt. Pura Apl. 46, 197-203 (2013).

6. C. J. Zapata Rodríguez, Problemas de Óptica Geométrica. Métodos Gráficos de Resolución, Visión Libros (2010).

7. C. J. Zapata Rodríguez and P. García-Martínez, Manual d'Óptica Geomètrica per al Traçat Gràfic de Raigs, Servei de Política Lingüística, Universitat de València (2011).

8. D. Brown and A. J. Cox, "Innovative Uses of Video Analysis" Phys. Teach. 47145 (2009). 